\title{
Biotransformation of 3-Methylphthalate by Micrococcus sp. Strain 12B
}

\author{
By RICHARD W. EATON† AND DOUGLAS W. RIBBONS* $\ddagger$ \\ Departments of Microbiology and Biochemistry, University of Miami School of Medicine Miami, \\ Florida 33152, USA
}

(Received 23 March 1987; revised 13 May 1987)

\begin{abstract}
When Micrococcus strain 12B grown on $o$-phthalate was incubated with 3-methylphthalate, three compounds accumulated. These were shown to be 2-pyrone-3-methyl-4,6-dicarboxylic acid, 3,4-dihydroxy-6-methylphthalic acid, and 5-hydroxy-3-methylphthalic acid, all previously undescribed. A pathway for the formation of these compounds is proposed.
\end{abstract}

\section{INTRODUCTION}

Micrococcus sp. strain 12B, which was isolated from compost by enrichment for growth with dibutylphthalate (Eaton \& Ribbons, 1982b), is able to grow with several other phthalate esters as well as the phthalate anion. Washed suspensions of cells grown in the presence of phthalate are capable of oxidizing several phthalate analogues including 3-methylphthalate (Eaton \& Ribbons, 1982a; Ribbons et al., 1984). 3-Methylphthalate did not support growth of Micrococcus sp. strain 12B but it was transformed to several UV-absorbing products. This is believed to be the first report of the metabolism of 3-methylphthalate.

\section{METHODS}

Transformation of 3-methylphthalate. A 11 overnight culture of Micrococcus sp. strain $12 \mathrm{~B}$ in mineral salts medium ( $R$ medium) supplemented with phthalate $(0.2 \%, \mathrm{w} / \mathrm{v})$ and yeast extract $(0.02 \%, \mathrm{w} / \mathrm{v})$ was used to inoculate a 141 Microferm fermenter (New Brunswick) containing 91 of the same medium (Eaton \& Ribbons, $1982 b$ ). After overnight incubation at $30^{\circ} \mathrm{C}$ with stirring and forced aeration, cells were harvested as described by Eaton \& Ribbons (1982a) and subsequently resuspended in $6150 \mathrm{mM}-\mathrm{KH}_{2} \mathrm{PO}_{4} / \mathrm{NaOH}$ buffer, pH 6.8 , in the Microferm fermenter. After the addition of $1.2 \mathrm{~g} \mathrm{3-methylphthalic} \mathrm{anhydride} \mathrm{(Eastman} \mathrm{Kodak)} \mathrm{cells} \mathrm{were}$ incubated at $30^{\circ} \mathrm{C}$ with stirring and forced aeration. Progress of the transformation was monitored spectrophotometrically, and when it appeared complete after $20 \mathrm{~h}$, the cells were removed by centrifugation. The supernatant was concentrated to $200 \mathrm{ml}$ at $50^{\circ} \mathrm{C}$ in a rotary evaporator, acidified to $\mathrm{pH} 2$ with $\mathrm{HCl}$, and extracted three times with equal volumes of diethylether. After the ether extract was dried over $\mathrm{Na}_{2} \mathrm{SO}_{4}$, the ether was evaporated; the residue was dissolved in $3 \mathrm{ml}$ ethanol/water $(1: 1, \mathrm{v} / \mathrm{v})$ and applied to a column $(41 \times 2.5 \mathrm{~cm})$ of Sephadex LH-20 (Pharmacia) and eluted with the same solvent. Fractions were assayed by diluting them in $50 \mathrm{~mm}$ $\mathrm{KH}_{2} \mathrm{PO}_{4} / \mathrm{NaOH}$ buffer, $\mathrm{pH} 6.8$, and recording their UV-visible spectra. Peak fractions were pooled and, after removal of the solvent at $50^{\circ} \mathrm{C}$ under reduced pressure in a rotary evaporator, the compounds were identified.

Spectrometric identification of transformation products. UV and visible spectra were recorded with a Cary model $118 \mathrm{C}$ dual beam spectrophotometer. Proton magnetic resonance spectra were obtained by $\mathrm{R}$. Block of the Papanicolaou Cancer Research Institute (Miami, Florida, USA) with a Varian HA 100-D15 spectrometer at 100 MHz. Samples were dissolved in deuterated dimethylsulphoxide with tetramethylsilane as internal standard. Mass spectra of 3-methylphthalate transformation products $B$ and $C$ were obtained by $K$. Pfaffenberger of the Department of Epidemiology and Public Health, University of Miami (Florida, USA) with a Finnigan model $4000 \mathrm{GC} / \mathrm{MS}$ operating in the electron impact mode at $70 \mathrm{eV}$. The mass spectrum of 3-methylphthalate transformation product A was obtained by R. Bottcher of the Department of Chemistry, Florida State University (Tallahassee, Florida, USA) with an AEI MS 902 spectrometer operating in the electron impact mode.

\footnotetext{
† Present address: Pesticide Degradation Laboratory, ARS, USDA, Beltsville, Maryland 20705, USA.

$\ddagger$ Present address: Centre for Biotechnology, Imperial College of Science and Technology, London SW7 2AZ, UK.
} 


\section{RESULTS}

Washed cells of Micrococcus sp. strain 12B grown on phthalate transformed 3-methylphthalate (added as 3-methylphthalic anhydride) to products having an increased UV absorbance and a shift in the peak absorbance (Fig. 1). Three products of this transformation were separated by chromatography on Sephadex LH-20 (Fig. 2) and identified.

Product A. (75 mg.) This was identified as 2-pyrone-3-methyl-4,6-dicarboxylic acid (Fig. 3, compound VII), the lactone of 4-carboxy-2-hydroxy-5-methylmuconic acid (Fig. 3, compound VI). The compound melted at $236-238^{\circ} \mathrm{C}$, and did not give a colour with the phenol reagents $\mathrm{FeCl}_{3}$ and 2,6-dibromo- $N$-chloro- $p$-benzoquinoneimine or with the Evans (1947) catechol reagent.

The proton magnetic resonance spectrum of product $\mathrm{A}$ showed three methyl protons and a vinylic proton: $\delta_{\mathrm{H}}$ p.p.m. $2 \cdot 49(3 \mathrm{H}, \mathrm{s}), 7 \cdot 49(1 \mathrm{H}, \mathrm{s})$. The mass spectrum showed a parent ion $\left(\mathrm{M}^{+}\right)$ at $m / e 198$ with major fragmentation products at $m / e 180\left(M^{+}-\mathrm{H}_{2} \mathrm{O}\right), 153\left(M^{+}-\mathrm{COOH}\right)$ and $125\left(M^{+}-\mathrm{COOH}-\mathrm{CO}\right)$. Similar fragmentation products $\left(M^{+}-\mathrm{COOH}\right)$ and $\left(\mathrm{M}^{+}-\mathrm{COOH}-\mathrm{CO}\right)$ are present in the mass spectra of the related lactones 2-pyrone-6carboxylic acid (Eaton \& Ribbons, 1982b) and 2-pyrone-4,6-dicarboxylic acid (Eaton \& Ribbons, 1982 b; Maruyama, 1979). The UV spectra of product A have, at $\mathrm{pH} 2$, a maximum at $306 \mathrm{~nm}(\varepsilon 8320)\left(\varepsilon\right.$ is the molar absorption coefficient, units $1 \mathrm{~mol}^{-1} \mathrm{~cm}^{-1}$ ) with a shoulder at $229 \mathrm{~nm}(\varepsilon 6030)$; at pH 7, a maximum at $304 \mathrm{~nm}(\varepsilon 8510)$ with a shoulder at $218 \mathrm{~nm}(\varepsilon 8510)$; and at $\mathrm{pH} 12$, a maximum at $303 \mathrm{~nm}(\varepsilon 8320)$.

Product B. (120 mg.) This was identified as 3,4-dihydroxy-6-methyl-phthalic acid (Fig. 3, compound III). It gave an olive green colour with $\mathrm{FeCl}_{3}$, a purple colour with 2,6-dibromo- $N$ chloro-p-benzoquinoneimine, and a positive Evans (1947) test for catechols. In aqueous solution the compound was a fluorescent green under UV light as would be expected for an aromatic compound having a hydroxyl group ortho to a carboxyl group. The compound melted at 221$224^{\circ} \mathrm{C}$. The proton magnetic resonance spectrum showed $\delta_{\mathrm{H}} 2.64(3 \mathrm{H}, \mathrm{s})$ and $7.26(1 \mathrm{H}, \mathrm{s})$ consistent with a methyl group and an aromatic proton. The mass spectrum showed no parent ion at $m / e 212$ but there were major mass peaks at $m / e 194\left(M^{+}-\mathrm{H}_{2} \mathrm{O}\right), 150\left(M^{+}-\mathrm{CO}_{2}-\mathrm{H}_{2} \mathrm{O}\right)$ and $122\left(\mathrm{M}^{+}-\mathrm{CO}_{2}-\mathrm{CO}-\mathrm{H}_{2} \mathrm{O}\right)$. The UV-visible spectra of product $\mathrm{B}$ had at $\mathrm{pH} 2$, a maximum at $252 \mathrm{~nm}(\varepsilon 5940)$; at $\mathrm{pH} 7$, maxima at $399 \mathrm{~nm}(\varepsilon 7940), 306 \mathrm{~nm}(\varepsilon 2190)$, and $226 \mathrm{~nm}(\varepsilon 12300)$; and at pH 12, maxima at $429 \mathrm{~nm}(\varepsilon 10000)$ and $289 \mathrm{~nm}(\varepsilon 6920)$ with a shoulder at $330 \mathrm{~nm}(\varepsilon$ 2340).

Product C. (23 mg.) This was identified as 5-hydroxy-3-methyl-phthalic acid (Fig. 3, compound VIII). It gave a rose colour with 2,6-dibromo- $N$-chloro- $p$-benzoquinoneimine and a negative Evans test. The proton magnetic resonance spectrum in deuterated dimethylsulphoxide was consistent with three benzylic protons and two non-adjacent aromatic protons: $\delta_{\mathrm{H}} 2.62$ $(3 \mathrm{H}, \mathrm{s}), 6.89(1 \mathrm{H}, \mathrm{s}), 7.62(1 \mathrm{H}, \mathrm{s})$. The mass spectrum did not show a parent ion at $\mathrm{m} / \mathrm{e} 196 \mathrm{but}$ there were major mass peaks at $m / e 178\left(M^{+}-\mathrm{H}_{2} \mathrm{O}\right), 134\left(M^{+}-\mathrm{H}_{2}-\mathrm{CO}_{2}\right)$ and $106\left(M^{+}-\mathrm{H}_{2} \mathrm{O}-\right.$ $\mathrm{CO}_{2}-\mathrm{CO}$ ).

\section{DISCUSSION}

Some of the early enzymes of phthalate catabolism in Micrococcus sp. strain 12B are relatively non-specific and they catalyse the transformation of several ring-substituted analogs (Eaton \& Ribbons, 1982a; Ribbons et al., 1984) and ester derivatives (Eaton \& Ribbons, 1982c). Thus, phthalaldehydate is converted to 3,4-dihydroxyphthalaldehydate and dimethylphthalate gives 3,4-dihydroxyphthalate-2-methyl ester after incubation with induced cells. Both products lack a carboxyl group at the $\mathrm{C}-2$ position and are not substrates for the next enzyme of the pathway, 3,4-dihydroxyphthalate-2-decarboxylase. 3-Methylphthalate is a substrate analogue without this restriction and can be metabolized further. In the present study, this was documented by isolation of an oxidation derivative of the 4,5-ring cleavage product. 


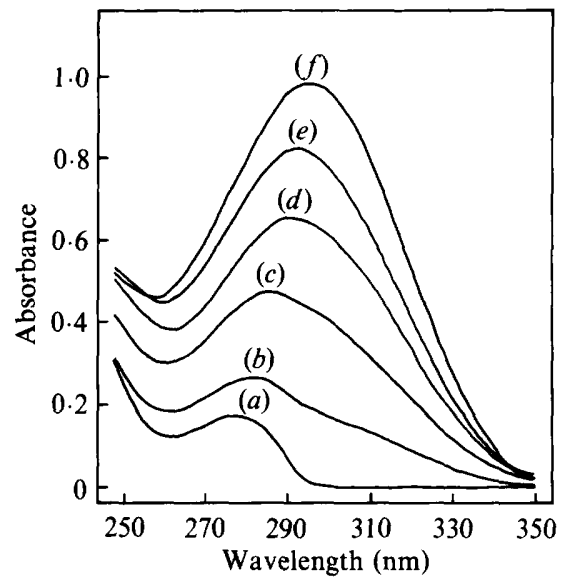

Fig. 1

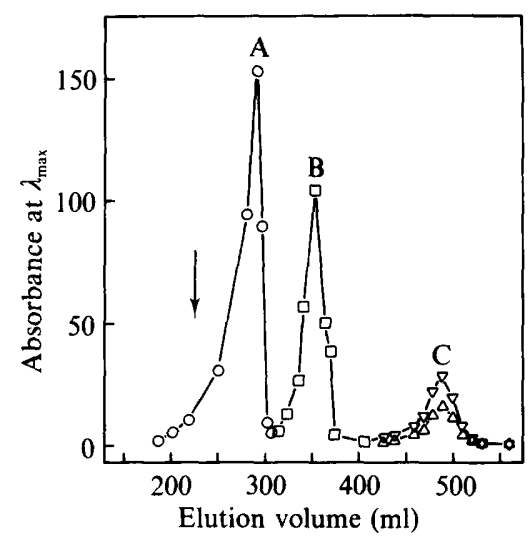

Fig. 2

Fig. 1. Transformation of 3-methylphthalate by Micrococcus sp. strain 12B. Washed suspensions of cells grown on phthalate were incubated with 3-methylphthalate as described in Methods. Samples were taken at: $0 \mathrm{~h}(a), 1.25 \mathrm{~h}(b), 3.5 \mathrm{~h}(c), 6.75 \mathrm{~h}(d), 8.75 \mathrm{~h}(\mathrm{e})$, and $17.5 \mathrm{~h}(f)$. Cells were removed by centrifugation and the UV spectra of the supernatants were recorded after 6-fold dilution in $50 \mathrm{~mm}$ $\mathrm{KH}_{2} \mathrm{PO}_{4} / \mathrm{NaOH}$ buffer, $\mathrm{pH} 6.8$.

Fig. 2. Separation of the products of the transformation of 3-methylphthalate by chromatography on Sephadex LH-20. Peak A had an absorbance maximum at $304 \mathrm{~nm}(\mathrm{O})$, peak B had an absorbance maximum at $314 \mathrm{~nm}(\square)$, and peak $C$ had absorbance maxima at $244 \mathrm{~nm}(\nabla)$ and $288 \mathrm{~nm}(\triangle)$. The solvent was ethanol/water $(1: 1, \mathrm{v} / \mathrm{v})$; the arrow indicates one column volume eluted.

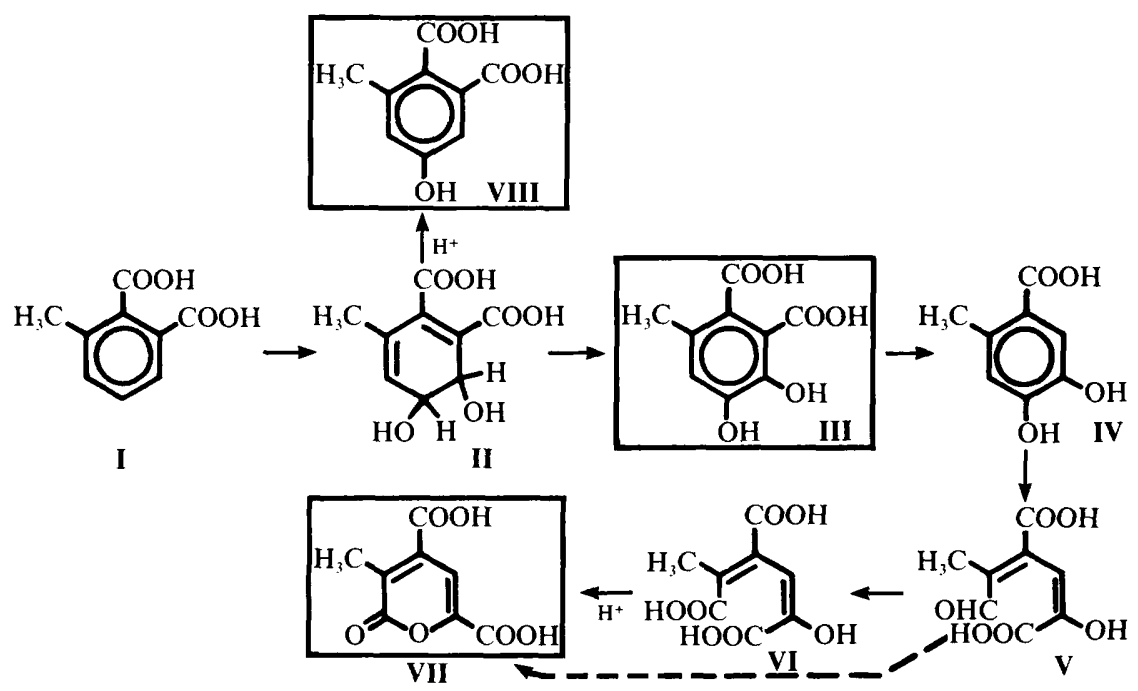

Fig. 3. Proposed pathway for the transformation of 3-methylphthalate by Micrococcus sp. strain 12B grown with phthalate. I, 3-Methylphthalate; II, 3,5-cyclohexadiene-3,4-diacarboxylate-5-methyl-1,2diol; III, 3,4-dihydroxy-6-methylphthalate; IV, 6-methylprotocatechuate; V, 4-carboxy-2-hydroxy-5methylmuconic semialdehyde; VI, 3-carboxy-5-hydroxy-2-methyloxalocrotonate; VII, 4,6-dicarboxy3-methyl-2-pyrone. 
The assignment of structures VII, III and VIII (Fig. 3) to the 3-methylphthalate transformation products A, B, and C, respectively, and the proposed reaction pathways for their formation were based on UV, mass and NMR spectra, on various colour reactions, and on the pathway shown to be used for phthalate catabolism in Micrococcus sp. strain 12B (Eaton \& Ribbons, 1982a, $b, c)$. Spectra obtained for product B indicated that it was 3,4-dihydroxy-6methylphthalate or 4,5-dihydroxy-6-methylphthalate. Structure III was assigned to product B since this compound was fluorescent, like 3,4-dihydroxyphthalate, the analogous metabolite from phthalate in Micrococcus sp. strain 12B; 4,5-dihydroxyphthalate, the Pseudomonas sp. intermediate in phthalate metabolism is not fluorescent.

The spectra obtained from product A were consistent with it being structure VII (Fig. 3). Compound VII could be formed during isolation by the spontaneous lactonization of 3-carboxy5-hydroxy-2-methylmuconate (Fig. 3, VI) or, alternatively, as the product of the enzymecatalysed dehydrogenation of compound $\mathrm{V}$ or its hemiacetal as shown for the protocatechuate 4,5-dioxygenase pathway in Pseudomonas testosteroni (Kersten et al., 1982). The former is consistent with the pathway proposed for phthalate metabolism in Micrococcus strain 12B (Eaton \& Ribbons, 1982b) in which compound VI would be the expected intermediate of 3methylphthalate metabolism while the latter possibility is suggested by the work of Maruyama $(1979,1983)$ who showed that in Pseudomonas ochraceae 2-pyrone-4,6-dicarboxylic acid, which is analogous to compound VII, is the product of an enzyme-catalysed dehydrogenation of the ring cleavage product, 4-carboxy-2-hydroxy-muconic semialdehyde, and an intermediate in phthalate metabolism in that organism.

Product $\mathrm{C}$ was identified as 4-hydroxy-6-methylphthalate (Fig. 3, compound VIII). By analogy with the transformations of phthalaldehydate and dimethylphthalate by dioxygenative hydroxylation (Eaton \& Ribbons, 1982a,c) in this strain, it is proposed that compound VIII arose as a non-enzymic dehydration product of the 3,4-dihydro-3,4-diol (Fig. 3, compound II) during acidification and extraction.

The overall yield of these products represents only $15 \%$ of the 3-methylphthalate provided to the culture. Other non-UV-absorbing intermediates may account for some of the balance. There was no attempt to optimize or quantify the accumulation and isolation of the three compounds produced by the wild-type Micrococcus sp. strain 12B.

This work was supported by grants EHS 00986 and GM 20172 from the National Institutes of Health.

\section{REFERENCES}

EAton, R. W. \& Ribbons, D. W. (1982a). The transformation of phthalaldehydate by Micrococcus sp. strain 12B. Archives of Biochemistry and Biophysics 216, 289-295.

Eaton, R. W. \& RibBons, D. W. (1982b). The metabolism of dibutylphthalate and phthalate by Micrococcus sp. strain 12B. Journal of Bacteriology 151, 48-57.

Eaton, R. W. \& Ribbons, D. W. (1982c). The metabolism of dimethylphthalate by Micrococcus $\mathbf{s p .}$ strain 12B. Journal of Bacteriology 151, 465-467.

Evans, W. C. (1947). Oxidation of phenol and benzoic acid by some soil bacteria. Biochemical Journal 41, 373-382.

Kersten, P. J., Dagley, S., Whittaker, J. W., ARCIERo, D. M. \& LiPSCOMB, J. D. (1982). 2-Pyrone- 4,6-dicarboxylic acid, a catabolite of gallic acids in Pseudomonas species. Journal of Bacteriology 152, 1154-1162.

MARUYAMA, K. (1979). Isolation and identification of the reaction product of $\alpha$-hydroxy- $\gamma$-carboxymuconic- $\delta$-semialdehyde. Journal of Biochemistry $\mathbf{8 6}$, 1671-1677.

MaruYaMa, K. (1983). Enzymes responsible for degradation of 4-oxalmesaconic acid in Pseudomonas ochraceae. Journal of Biochemistry 93, 567-573.

Ribbons, D. W., Keyser, P., Kunz, D. A., Taylor, B. F., EATON, R. W. \& ANDERSon, B. N. (1984). Microbial degradation of phthalates. In Microbial Degradation of Organic Compounds, pp. 371-393. Edited by D. T. Gibson. New York: Marcel Dekker. 